\title{
Steam Generator Tube Rupture Simulation Using Extended Finite Element Method
}

\author{
Subhasish Mohanty, Saurin Majumdar, and Ken Natesan \\ Nuclear Engineering Division, Argonne National Laboratory, Lemont 75309, USA
}

\begin{abstract}
A steam generator (SG) is an important component of any pressurized water reactor. Steam generator tubes represent a primary pressure boundary whose integrity is vital to the safe operation of the reactor. SG tubes may rupture due to propagation of a crack created by mechanisms such as stress corrosion cracking, fatigue, etc. It is thus important to estimate the rupture pressures of cracked tubes for structural integrity evaluation of SGs. The objective of the present paper is to demonstrate the use of extended finite element method capability of commercially available ABAQUS software to model SG tubes with preexisting flaws and to estimate their rupture pressures. For the purpose, elastic-plastic finite element models were developed for different SG tubes made from Alloy 600 material. The simulation results were compared with experimental results available from the steam generator tube integrity program (SGTIP) sponsored by the United States Nuclear Regulatory Commission (NRC) and conducted at Argonne National Laboratory (ANL). A reasonable correlation was found between extended finite element model results and experimental results.
\end{abstract}

\section{Introduction}

In the United States, the long-term sustainability of light water reactors (LWRs) is increasingly becoming an important issue because many of the operating reactors have either reached or are close to reaching their design life of 30-40 years. For economical reasons, it is desirable to keep operating these reactors for a longer duration, say up to 60-80 years [1]. However, stress corrosion cracking (SCC) and associated structural integrity issues are a major concern for the long-term sustainability of LWRs $[2,3]$. Under the auspices of the Department of Energy (DOE)'s light water reactor sustainability (LWRS) research program, ANL is currently investigating stress corrosion cracking and fatigue-related issues in the piping and tubing material of a reactor coolant system. Steam generator tubes constitute a critical part of the primary coolant pressure boundary. These tubes often crack by SCC and thermal fatigue. These cracks may initiate from either the inner or the outer surface of the tube, depending on the environmental exposure and stress levels. Initially, these cracks are part-through-wall (PTW) but can eventually become $100 \%$ through-wall (TW) either due to normal operating loading or due to transient pressure loading during design-basis or severe accident conditions. To guard against catastrophic failure, the NRC requires utilities to conduct periodic in-service inspections to detect cracks and, if detected, take proper remedial actions to ensure and demonstrate, by calculations or in-situ pressure tests, that adequate safety margins are maintained against burst and leakage throughout the component's lifetime during normal operation and various accident scenarios. Therefore, it is essential to be able to estimate, reliably, the rupture pressure of a tube with a PTW/TW crack. In general, the tube rupture pressure or time to failure of a tube is estimated by extensive laboratory tests [4] or by combined use of empirical methods [5] and finite element (FE) techniques [6-10]. Tube rupture modeling by the conventional finite element method (FEM) is cumbersome, particularly for modeling continuous crack initiation and crack propagation. Conventional FEM requires remeshing of the crack tip FE domain after each crack propagation increment 
and knowledge about the crack path beforehand. In reality, the crack path is not known a-priori. An efficient crack propagation model requires the crack path to be solution dependent or automatic. In conventional FEM, at each time interval during which the crack grows, the element boundary has to be aligned along the crack path, which may or may not always be the case in practice. Further, conventional FEM often fails to converge while modeling discontinuities such as at crack tips. All of the abovementioned limitations restricted the use of conventional FEM for modeling a moving crack tip.

The advancement of the extended finite element method or popularly known as XFEM technique and other similar technique such as meshfree modeling techniques, immersed particle method, etc. have made it possible to model moving cracks efficiently. The details development related to these techniques can be found from the literature [11-30]. In the present work rather than focusing on the further fundamental development aspect of XFEM and related methods, the application aspect of XFEM technique is explored for solving real-life engineering and regulatory issues. In the present work, the use of XFEM available through commercially available ABAQUS software is explored for modeling crack initiation and propagation in SG tubes and then to estimate the rupture pressure of tubes under a increasing pressure transient similar as in case of severe accident conditions. The results were compared with the experimental results [4] available under ANL's SGTIP program sponsored by the NRC. The SG tube FE model and results are discussed below.

\section{Theoretical background}

\subsection{XFEM modeling with ABAQUS}

The generic displacement field considered in XFEM based crack propagation modeling has the following form [14-18]:

$$
\begin{aligned}
u & =\sum_{i}^{n^{q}} N_{i}(x) q_{i}+\text { enriched function } \\
& =\sum_{i=1}^{n^{q}} N_{i}(x) q_{i}+\sum_{i=1}^{n^{a}} N_{i}(x) H(x) a_{i}+\sum_{i=1}^{n^{b}} N_{i}(x) \sum_{\alpha=1}^{4} F_{\alpha} b_{i}^{\alpha}
\end{aligned}
$$

where $N_{i}(x)$ and $q_{i}$ respectively, are the usual nodal shape functions and nodal degree-offreedom (DOF) vector used in conventional FEM and associated with the continuous finite elements; $H(x)$ and $a_{i}$ respectively, are the Heaviside function and nodal-enriched DOFs applies to elements, which are cut by crack interior. The Heaviside function $H(x)$ has a value of +1 or 1 depending on the location of cracked domain whether or not above or below the crack surface. Whereas in Eq. (1), $F_{\alpha}$ and $b_{i}^{\alpha}$ respectively, are the additional asymptotic crack tip functions and the associated enriched-nodal DOFs applies to element, which is cut by crack tip. In Eq. (1), ${ }_{n}^{q},{ }_{n}^{a}$ and ${ }_{n}^{b}$ respectively, represent the nodes associated with conventional FE model without presence of crack, nodes of the elements which are cut by crack interior and the node belong to the element that contains the crack tip.

In the discussed work, the steam generator tubes were modeled using the XFEM capability of commercially available ABAQUS software. ABAQUS's XFEM capability can model both 
stationary and nonstationary crack. For stationary crack modeling, the used version of the ABAQUS software uses both asymptotic enriched functions to model crack-tip singularity and nodal jump or Heaviside function (Phantom node modeling approach) to model finite elements, which are cut by crack interior. However, for modeling non-stationary crack (or propagating crack) ABAQUS uses only nodal jump or Heaviside function to model the finite elements, those are cut by crack interior. That is the used version [31] of the ABAQUS does not consider or allow modeling the asymptotic crack tip singularity associated with a propagating crack. For the purpose the crack has to propagate across an entire element at a time to avoid the need to model the stress singularity. Furthermore, for crack propagation modeling within the framework of XFEM, ABAQUS uses cohesive segment approaches based traction-separation techniques [32, 33]. Hence in combination, the phantom node and cohesive segments based approaches are used for modeling the present crack propagation in SG tubes. According to ABAQUS implementation of XFEM, first the crack has to initiate based on certain criteria. Once the crack initiate, the crack evolution is decided based on traction-separation techniques. For the crack propagation modeling the crack plane is assumed solution-dependent and perpendicular to the direction of the maximum principal stress. This allows the crack propagation model can handle a changing crack plane and crack propagation direction. The details of XFEM implementation in ABAQUS can be referred from ABAQUS user manual [31]. Below the crack initiation and propagation criteria are briefly discussed.

\subsection{Crack initiation criteria}

Crack initiation starts in an enriched element once the stresses or the strains satisfy certain crack initiation criteria. In ABAQUS ddifferent initiation criteria can be defined in terms of solutiondependent stress, strain, and the respective critical values. In the present work, the maximum principal stress criterion is used for the initiation of the crack in a element. This criterion is given below:

$$
f=\frac{\left\langle\sigma_{\max }^{p}\right\rangle}{\sigma_{c r}^{p}}=\left\{\begin{array}{l}
\geq 1+f_{\text {tol }} \\
<1+f_{\text {tol }}
\end{array} \quad \begin{array}{c}
\text { crack will initiate } \\
\text { crack will not initiate }
\end{array}\right.
$$

where $\sigma_{\max }^{p}$ is the solution-dependent maximum principal stress, $f_{\text {tol }}$ is the tolerance value (a default value of 0.05 used for all the discussed results), and $\sigma_{c r}^{p}$ is the critical principal stress, which has to be provided as an input material property. In Eq. (2), the symbol \langle\rangle represents Macaulay brackets with $\left\langle\sigma_{\max }^{p}\right\rangle=0$ if $\sigma_{\max }^{p}<0$, i.e., when the maximum principal stress is purely compressive. In the present work the critical principal stress assumed equal to the flow stress of material and is given as:

$$
\sigma_{c r}^{p}=0.5\left(\sigma_{y}+\sigma_{u}\right)
$$


where $\sigma_{y}$ and $\sigma_{u}$ are respectively, the yield and ultimate stress of material. Note that according to the proposed crack initiation criteria and for the considered material (Alloy 600), crack will only initiate when the stress in the structure is beyond yield strength (refer Table 1). In other word, the crack will only initiate in an element when there is plastic deformation in that element. Also to note that, there was no singularity issues associated with crack tip since crack initiation criteria was checked based on the solution-dependent maximum principal stress value at the centroid of the element that to be cracked. The crack has to propagate across the entire element at a time if the crack initiation criterion was satisfied. Once the crack propagates through an element the crack tip either has to stay at the boundary of that element or to make it totally open. If the crack tip is at the boundary of a cracked element, unless the crack initiation criteria satisfied in the enriched element ahead of the crack tip, the crack tip remain stagnant to its original location. Also note that, the crack plane is solution-dependent and is perpendicular to the direction of the maximum principal stress. This allows crack propagation with changing crack plane.

\subsection{Crack evolution through traction separation criteria}

Crack evolution criterion describes the rate at which traction is applied to the cracked surface of the cracked element following initiation. Once a crack initiation criterion is met, damage can propagate according to the traction separation based damage evolution techniques [32-35]. Note that if a crack initiation criterion is not satisfied in an element the stress-strain states in an element are estimated through conventional FE based elastic-plastic stress analysis. However, if damage initiation criteria satisfied for a particular element, first the normal and shear components of traction are predicted elastically (based on elastic properties) assuming no damage in the element. Then the normal and shear components of the traction affected by the damage can be predicted according to the following expression:

$$
\begin{aligned}
& t_{n}=\left\{\begin{array}{c}
(1-D) T_{n}, T_{n} \geq 0 \\
T_{n}, T_{n}<0
\end{array}\right\} \\
& t_{s}=T_{s}, \\
& t_{t}=T_{t}
\end{aligned}
$$

Where, $t_{n}, t_{s}$ and $t_{t}$ represent the normal, first and second shear component tractions assuming damage. Whereas, $T_{n}, T_{s}$ and $T_{t}$ represent the normal, first and second shear component tractions assuming no damage. In Eq. (4) the scalar damage variable $D$ represents the extent of damage in an element at a given loading step. The damage variable $D$ monotonically evolves after the initiation of damage, with a starting value of 0 to a maximum value of one based on the extent of loading at a given instant. In the discussed work the damage evolution $D$ has to be estimated based on the energy that is dissipated as a result of the damage process, also called the fracture energy. The critical fracture energy or the fracture toughness is equal to the area under the traction-separation curve as shown in Figure 1. For simplicity, 
assuming linear traction separation behavior, the critical fracture energy or fracture toughness $G_{c r}$ can be expressed as

$$
G_{c r}=\frac{1}{2} t_{0} \delta_{f}
$$

where $\delta_{f}$ and $t_{0}$, respectively are the separation displacement at failure and the traction at damage initiation.

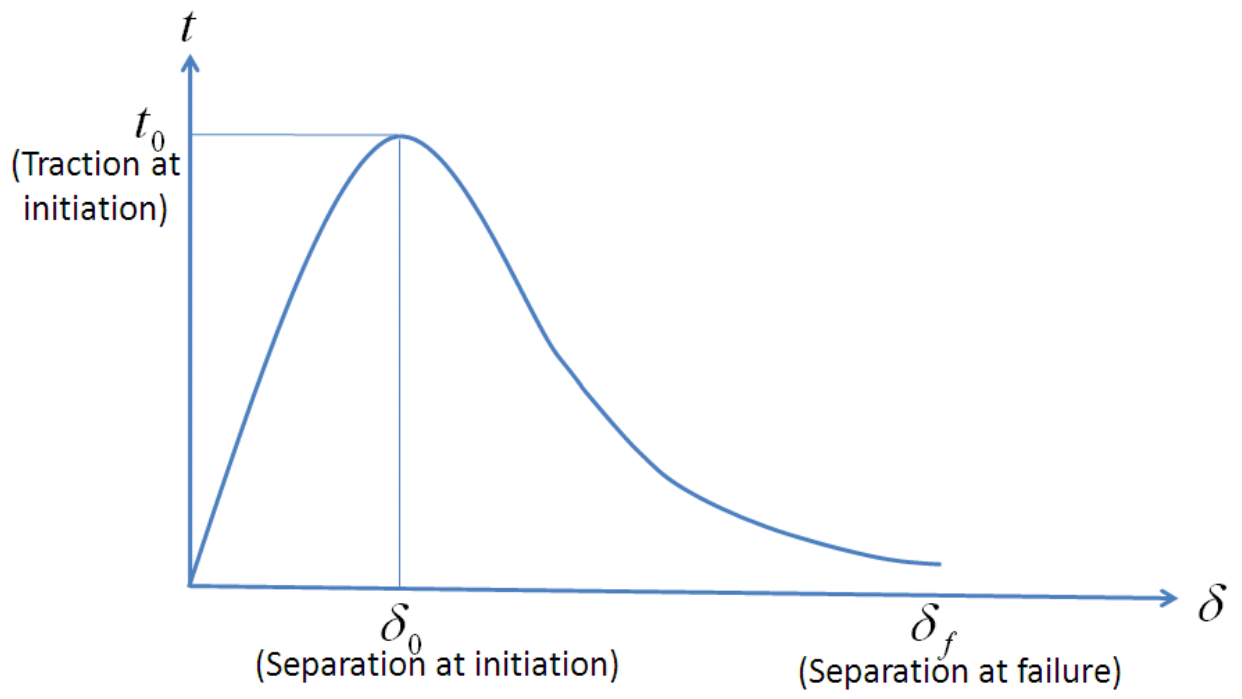

Figure 1 Schematic of traction separation curve

\section{SG Tube FE Model Results}

The above-discussed XFEM technique was used to model crack initiation and propagation in SG tubes under pressure transients at room temperature. The results are compared with the experimental data obtained through the NRC-sponsored SG tube integrity experiments conducted at ANL. Multiple Alloy $600 \mathrm{SG}$ tubes were tested under different pressure conditions, and the details of these tests can be found in NUREG/CR-6804 [4]. In the present work, only a few prototypical cases are considered to verify the capability of the XFEM modeling techniques. The details of the model and results are discussed below for two different cases: 1) Tube with single initial crack, 2) Tube with two initial cracks.

\subsection{SG tube model with single initial crack}

In nuclear plants, SG tubes containing preexisting SCC cracks may start to grow due to a pressure transient (e.g. as in case of severe accident conditions) when the internal pressure reaches a critical value. These cracks may have a complex shape that is difficult to replicate through simulation models and laboratory tests. Therefore, the tests were conducted on welldefined rectangular notches, which are typically much wider $(0.1-0.3 \mathrm{~mm})$ than SCCs. However, the notches were modeled as sharp cracks. In the first case, SG tube models were developed with 
a single preexisting PTW axial crack from the outer diameter (OD) surface. The tubes had an OD of $22.2 \mathrm{~mm}$ (7/8 in.), and a thickness of $1.27 \mathrm{~mm}$ and were made from Alloy 600 material. The material properties considered for the present FEM are given in Table 1, and the stress-strain curve used for the simulation is shown in Figure 2. The mentioned stress-strain data was obtained from the in-house tensile test using Alloy 600 specimen. For the FE model 3D brick elements were used to model the SG tubes. The initial crack was modeled as a shell or planar geometry and superimposed on the tube geometry. A typical FEM of an SG tube is shown in Figure 3. The model includes a PTW OD axial crack with length of $6.35 \mathrm{~mm}$ and a ratio for the crack depth to tube wall thickness $(\mathrm{a} / \mathrm{h})$ of $75 \%$. In the FEM, the geometric and force boundary conditions are applied such that they are equivalent to the experimental boundary conditions (refer [4]). In the NRC-sponsored SG tube integrity experiments, one end of the SG tube was fixed to the fluid flow path, whereas the other end was plugged to help build up the pressure inside the tube. As in the experimental conditions, the FEM model inner surface was subjected to an increasing pressure. In addition, an equivalent longitudinal pressure applied to the end plug was used to simulate the far-field biaxial stress field. Crack initiation (at existing notch) and propagation were simulated for an increasing applied internal pressure. Note that the propagation of the initial crack does not occur immediately after the pressurization starts. The crack may start to grow only after a critical pressure is reached.

Table 1 Room-temperature material properties for Alloy 600

\begin{tabular}{|c|c|}
\hline Elastic modulus $(\mathrm{GPa})$ & 200 \\
\hline Poisson's ratio & 0.3 \\
\hline Yield strength $\sigma_{y}(\mathrm{MPa})$ & 296 \\
\hline Ultimate strength $\sigma_{u}(\mathrm{MPa})$ & 684 \\
\hline Critical principal stress $(\mathrm{MPa}) \mathrm{in} \mathrm{Eq.} \mathrm{(3)}$ & 490 \\
\hline Critical fracture energy $G_{c r}\left(\mathrm{~kJ} / \mathrm{m}^{2}\right)$ in Eq. (5) & 415 \\
\hline
\end{tabular}




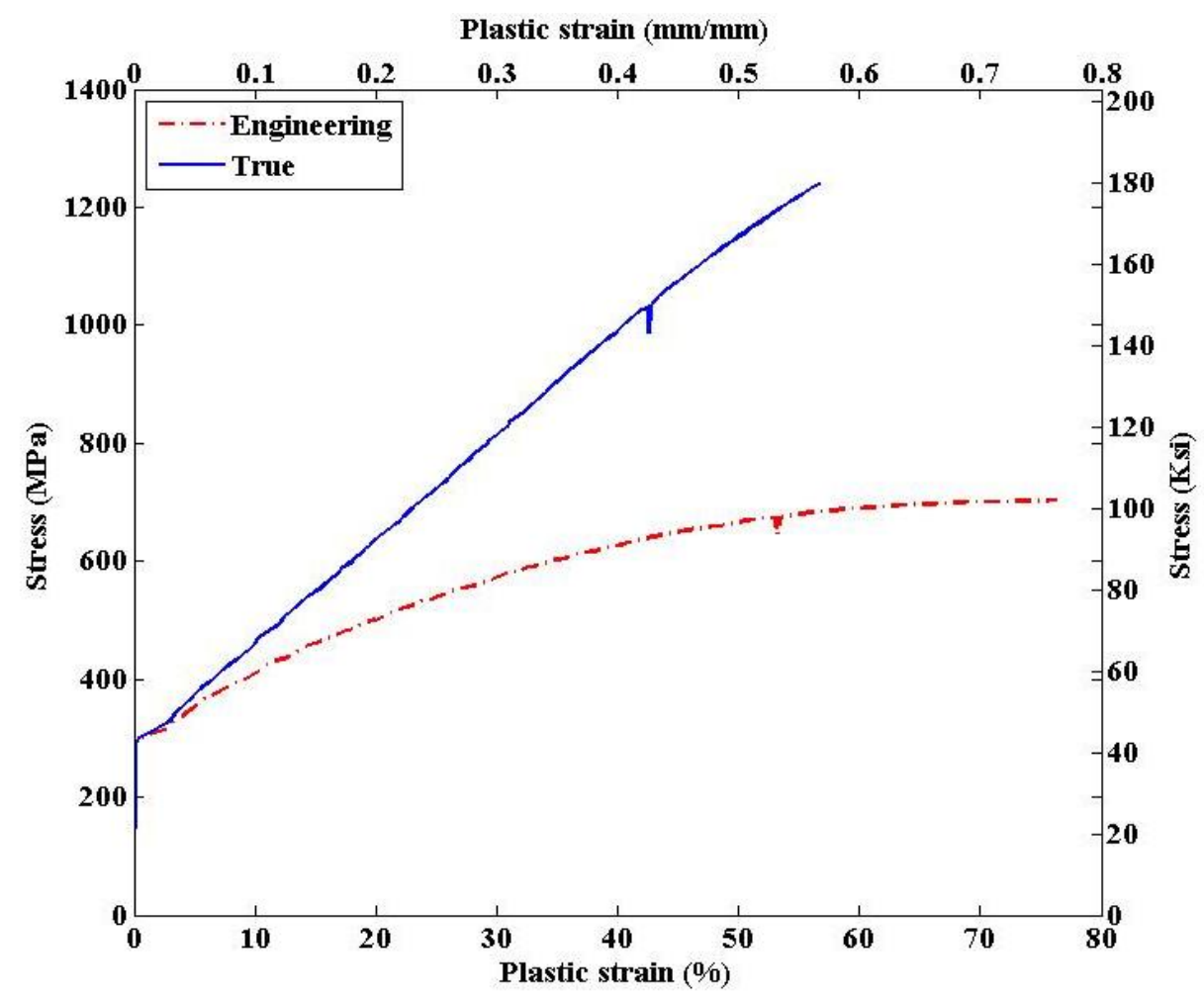

Figure 2 Room-temperature stress-strain curves for Alloy 600

a)

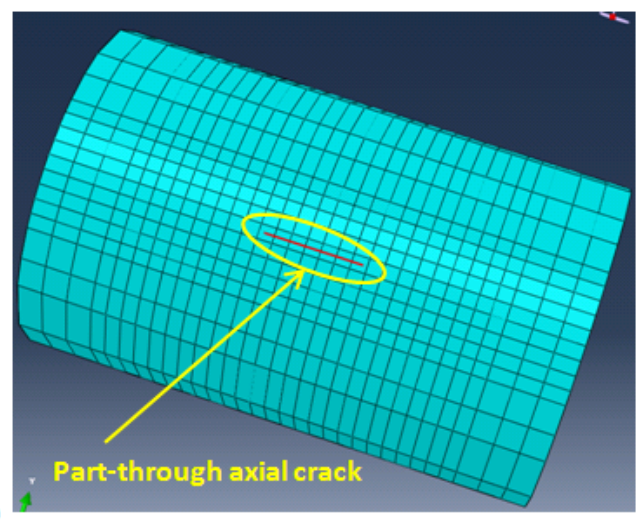

Figure 3 Typical FEM model of a 22.2-mm (7/8-in.) OD tube with an initial crack length of $6.35 \mathrm{~mm}$ and crack depth to wall thickness ratio of 75\%: (a) OD surface and (b) cut section of the cross section

In the XFEM model, the critical pressure at which the crack begins to grow can be estimated from the solution-dependent maximum principal stress when it equals or exceeds the limiting critical principal stress $\sigma_{c r}^{p}$, as given by Eq. (3). The predicted ligament rupture and final burst pressures based on this assumption match the corresponding experimental values reasonably well. The details of the findings are discussed further below. 
For the FEM model shown in Fig. 3, the maximum principal stress distribution at an applied pressure of $24.66 \mathrm{MPa}$ is shown in Fig. 4. The simulation results indicate that the crack begins to propagate along the radial or wall thickness direction at this pressure. They also indicate that the maximum principal stress at the crack tip element exceeds the limiting principal stress $\left(\sigma_{c r}^{p}\right)$ of $490 \mathrm{MPa}$ (refer Table 1). Note that to check the crack initiation criteria (refer section 2) in a given element, the principal stress estimated at centroid of that element is compared with the limiting principal stress. After initiation, the crack grows further in the radial direction (along the thickness) and ruptures the last ligament in the inner diameter (ID) surface. The corresponding applied pressure is referred to here as "ligament rupture pressure." After the ID ligament ruptures, the crack grows further unstably in the axial and radial directions with increasing pressure, until the FEM calculation fails to converge because of issues associated with large plastic deformation. The corresponding applied internal pressure is referred to as the "burst pressure." For the FEM model shown in Fig. 3, the estimated ID ligament rupture and burst pressure were found to be $37.73 \mathrm{MPa}$ and $40.01 \mathrm{MPa}$, respectively. The corresponding experimental values were reported as 36.5 and $41.2 \mathrm{MPa}$, respectively, showing a good correlation between the XFEM model and experimental results. Figures 5a and 5b show the corresponding OD surface shape at the ligament rupture pressure and burst pressure, respectively. An experimental (in-house test conducted under the NRC-sponsored SG tube integrity program [4]) specimen with similar initial crack shape after bursting, shown in Fig. 6, has a remarkably similar geometry to the FEM-predicted shape (Figure 5b). Since the FE model stopped in between the simulation due to the large plastic deformation during the instantaneous final burst the shape of the FE model shown in Figure $5 b$ is not an exact match of the experimental shape shown in Figure 6. The experimental image shows the shape of the tube after final unstable burst. From this figure it can be seen that the crack tips are $45^{\circ}$ inclined with respect to axial direction. Although this final shapes resembles a typical shear stress dominated ductile crack growth, the overall crack growth could have dominated by both normal and shear stress. Despite, this experimental observation by comparing Figure 6 with Figure 5 it can be seen that, there is a remarkably similarity between experiment and FEM-predicted shapes. As mentioned before (refer section 2.2), the crack plane in XFEM model is solution-dependent and is estimated as perpendicular to the direction of the maximum principal stress. Note that the tube integrity test was conducted in two stages. In first stage, the pressurization test was conducted until the ID ligament rupture and subsequent pressurized water leaking made it impossible to continue the tests. In the second stage (after the ID ligament rupture), a Silicone bladder was inserted into the SG pipe and the pressurization was restarted until the unstable burst occurred. Figure 6 shows the experimental specimen after the second stage of pressurization test. For simplicity, in the discussed FE models neither the effect of the internal bladder nor the pressure loading on the crack surface are modeled. Figure 7 shows the crack opening displacement (COD) at the OD and ID surface, which is time dependent (or applied pressure dependent). It shows that, although the COD is larger for the OD than the ID, both values increase unstably after the ID ligament rupture. Figure 8 shows the estimated equivalent plastic strain with respect to applied pressure at a radial crack-tip element (in front of the initial crack) and at a central ID ligament element. Figures 7 and 8 both show that the COD and the maximum equivalent plastic strain behave in a similar manner with increasing pressure. In addition to the above-mentioned model, other tube models were developed parametrically with different initial crack lengths and crack depth to wall thickness ratios (a/h). Some of these results are depicted in Figures 9 and 10. For example, Figure 9 shows the radial crack initiation pressure and ID ligament rupture 
pressure as functions of $\mathrm{a} / \mathrm{h}$. As $\mathrm{a} / \mathrm{h}$ increases, the corresponding radial crack initiation and ID ligament rupture pressures decrease non-linearly. Similar trends can also be seen with increasing initial crack length, as shown in Figure 10.

To check the effect of different finite element size on simulation results, a mesh sensitivity study was performed. The mesh sensitivity study was conducted considering different element size along the thickness, circumferential and axial direction of the tube. For the meshing purpose the tube was divided axially and circumferentially in to two regions. In the circumferential direction, $\pm 22.5^{\circ}$ about the axial crack centerline was modeled with finer mesh and rest of the circumference was modeled with coarser mesh. Similarly along the axial direction, $\pm 12.5 \mathrm{~mm}$ from center of the axial crack was modeled with finer mesh, whereas rest of the tube along axial direction was modeled using coarser mesh. For the coarser mesh region, the sizes of the finite elements along the axial and circumferential direction were kept as $1.67 \mathrm{~mm}$ and $4.33 \mathrm{~mm}$, respectively. The details of the elements size in finer mesh region are given in Table 2. Note that other than the mesh sensitivity study, to avoid long simulation time, the size of the FE mesh was restricted within the limit of total 50,000 elements. This is because of the lack of computational resource such as constraints in using multiple ABAQUS licenses for multiprocessor simulation. Note that most of the simulations discussed in this paper, were conducted using a 6 processor ABAQUS license with approximate simulation time of 6 to 8 hours. For mesh sensitivity analysis five FE models were created. Table 2 shows the size of elements for different cases and the corresponding estimated ligament rupture pressure. Note that the corresponding detailed results for case-A (refer Table 2) has already been discussed (refer Figures 3-9). For mesh sensitivity out of the total 5 test cases (A-E) the FE simulations were performed for four cases except case-B. The simulation of case-B was not performed because of the large number of elements, which would require longer computational time. However, the intent of mentioning this case is to show the size of the FE problem if just the size of FE mesh reduced by 10 times along the axial direction. Since the thickness of the tube is $1.27 \mathrm{~mm}$ and the crack depth to wall thickness ratio is of $75 \%$, it is essential to model the remaining (along the thickness) ligament with smaller size for accurate crack propagation along thickness direction. At the same time this restriction hinders to decrease the mesh size along other direction to avoid overall increase of number of elements. Nevertheless the purpose of this mesh sensitivity study was to know how the mesh density affects the simulation FE results. For example Table 2 shows the estimated ligament rupture pressure for case A, C, D and E. From these results it can be seen that the simulated ligament rupture pressure are well comparable to each other and with the corresponding experimental value of $36.5 \mathrm{MPa}$. Furthermore Figure 11 shows the simulated maximum principal stress history at the central (at center of crack) ID element for various test cases A, C, D and E. From this Figure it can be seen that even with a higher mesh density case C has similar principal stress history with comparison to case A. With this observation and with constraint of computational resources, the FE mesh size for all the test cases (unless specifically mentioned) were kept same as the FE mesh size of case -A in table 2. 


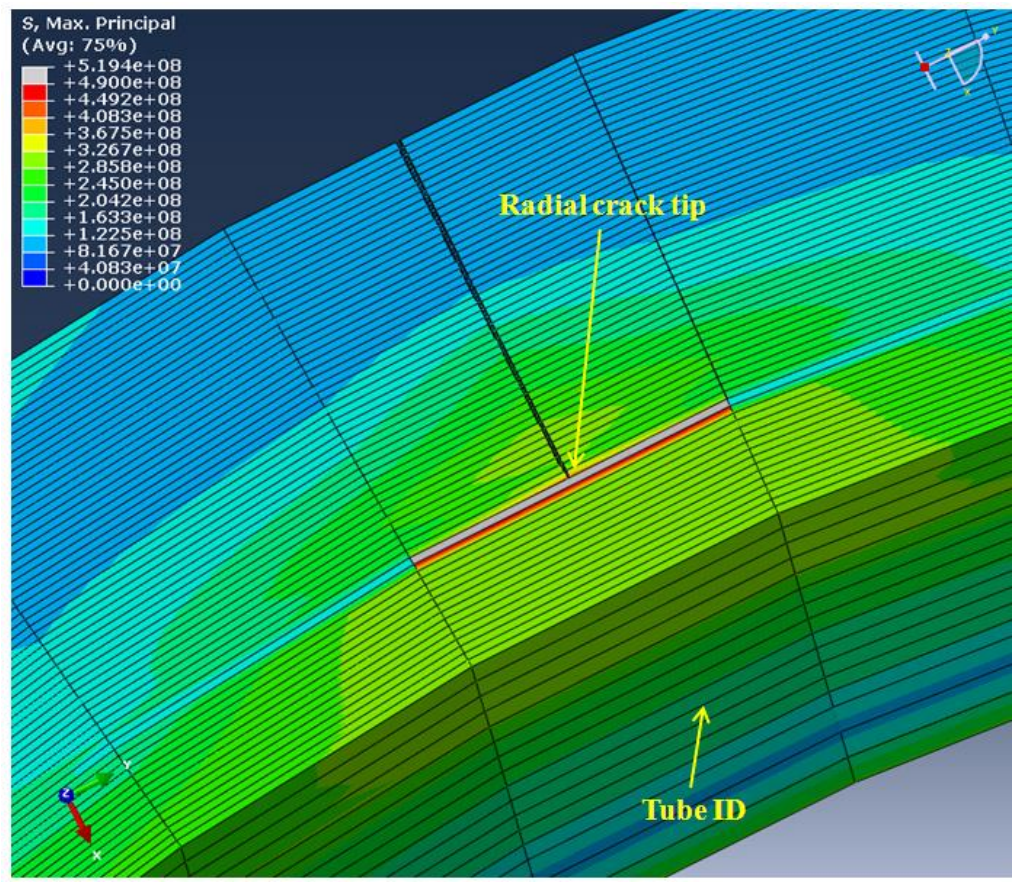

Figure 4 Maximum principal stress distribution upon exceeding the critical principal stress $\sigma_{c r}^{p}$ just before crack initiation or cracking of the crack-tip element in front of initial crack in radial direction

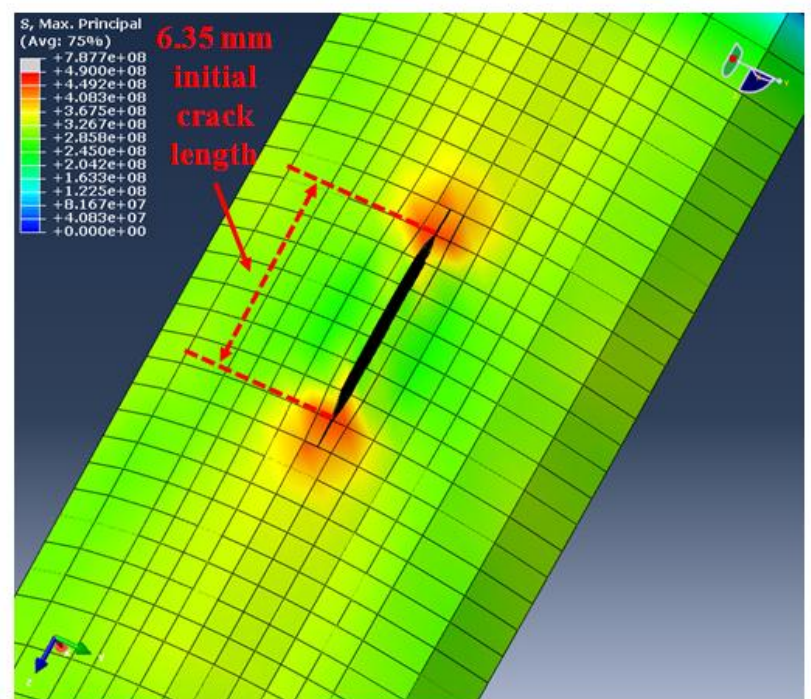

a)

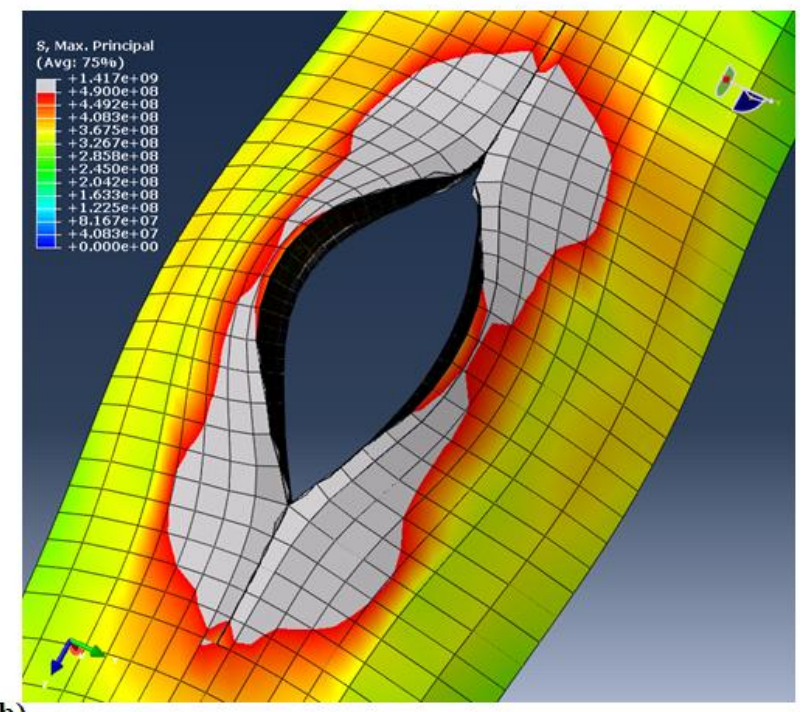

b)

Figure 5 Shape of the OD surface and maximum principal stress distribution for the model shown in Fig. 5 at (a) ID ligament rupture pressure (37.5 MPa) and (b) final burst pressure (40.01 $\mathrm{MPa})$ 

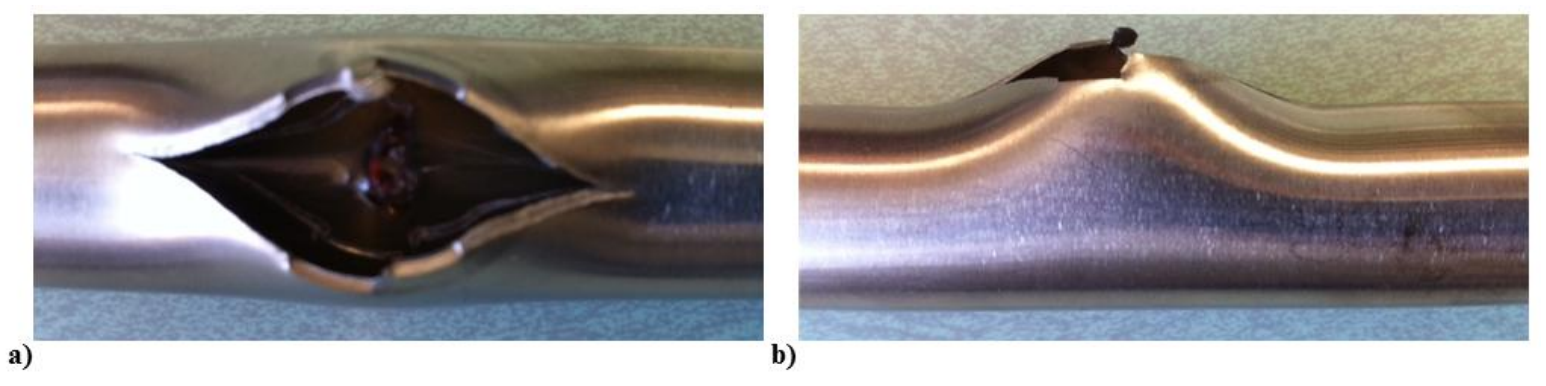

Figure 6 After-burst shape of a typical 22.2-mm diameter tube with 6.35-mm initial notch: (a) top view and (b) side view (the in-house test conducted under the NRC-sponsored SG tube integrity program [4])

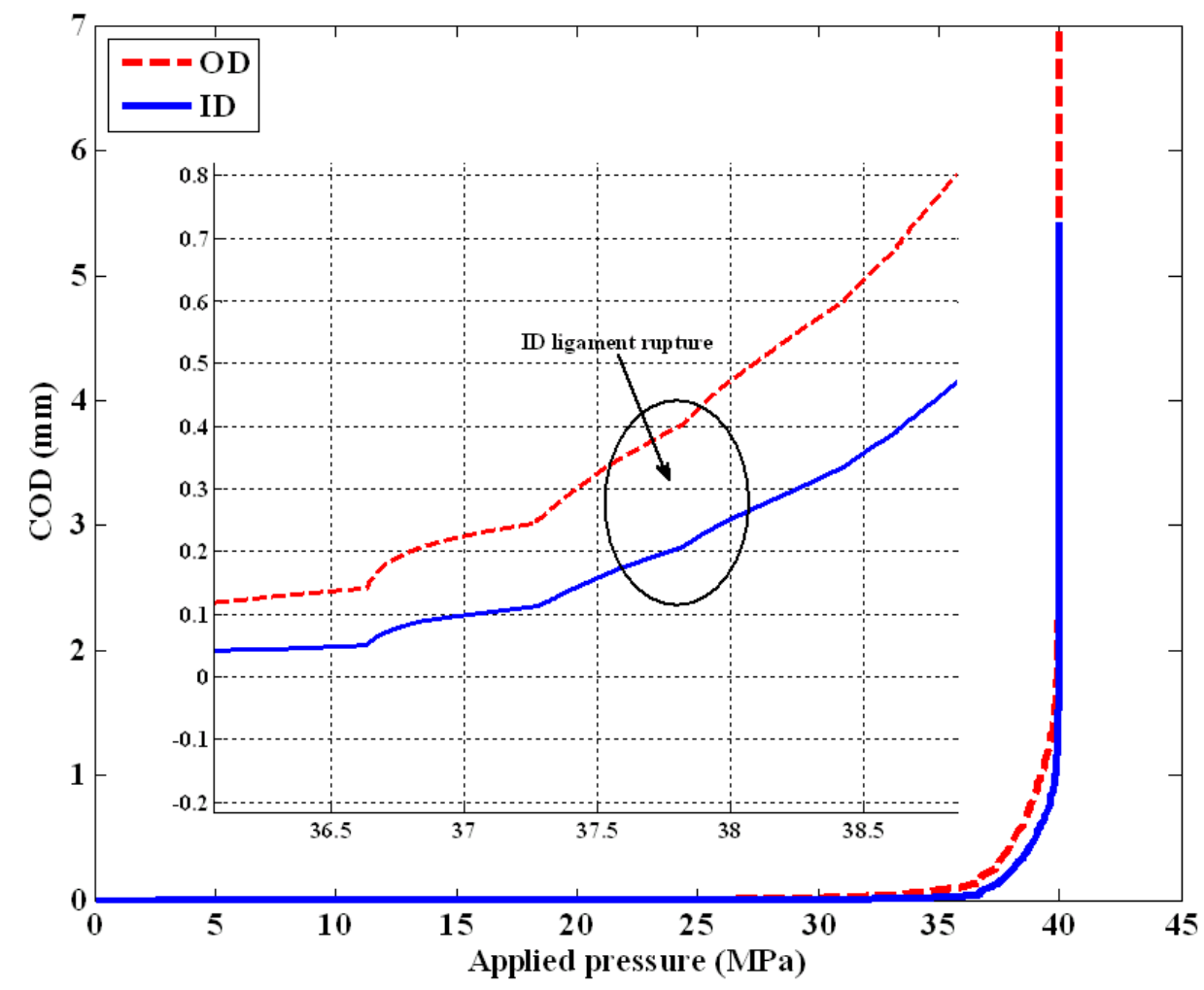

Figure 7 Estimated COD with respect to applied pressure at the OD and ID surface of the 22.2$\mathrm{mm}$ OD tube (the inside superimposed figure shows the magnified COD evolution between 36$39 \mathrm{MPa}$ of applied pressure) 


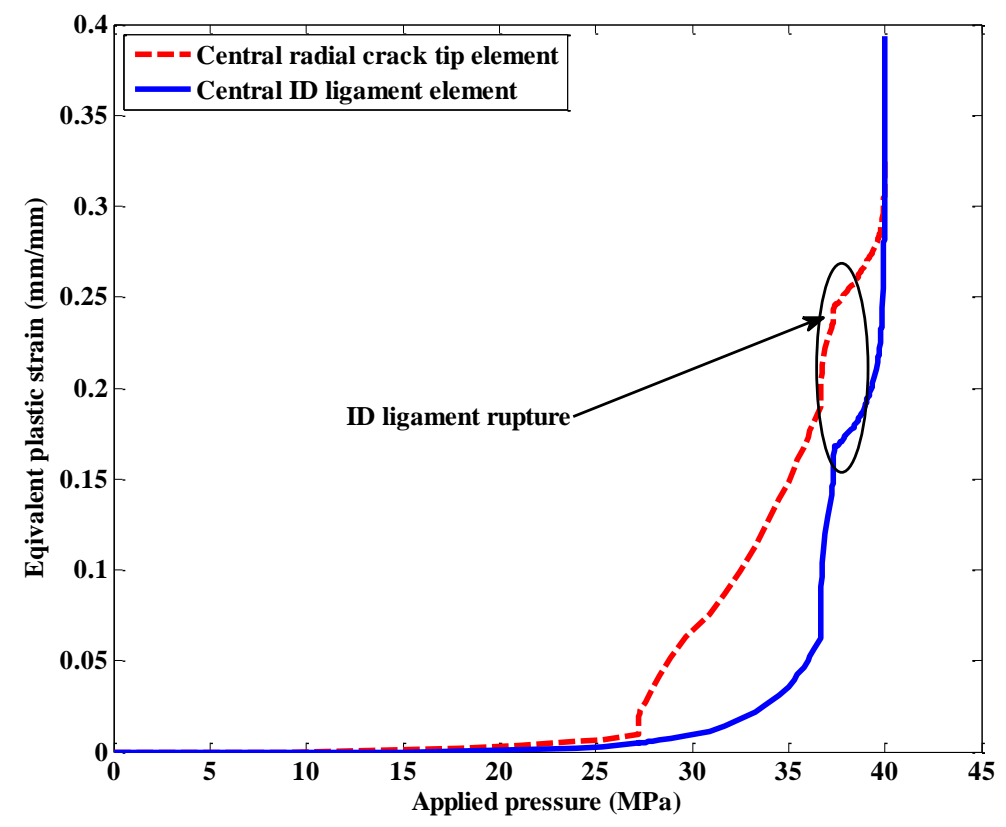

Figure 8 Estimated equivalent plastic strain with respect to applied pressure at radial crack-tip element (in front of the initial crack) and central ID ligament element of the 22.2-mm OD tube

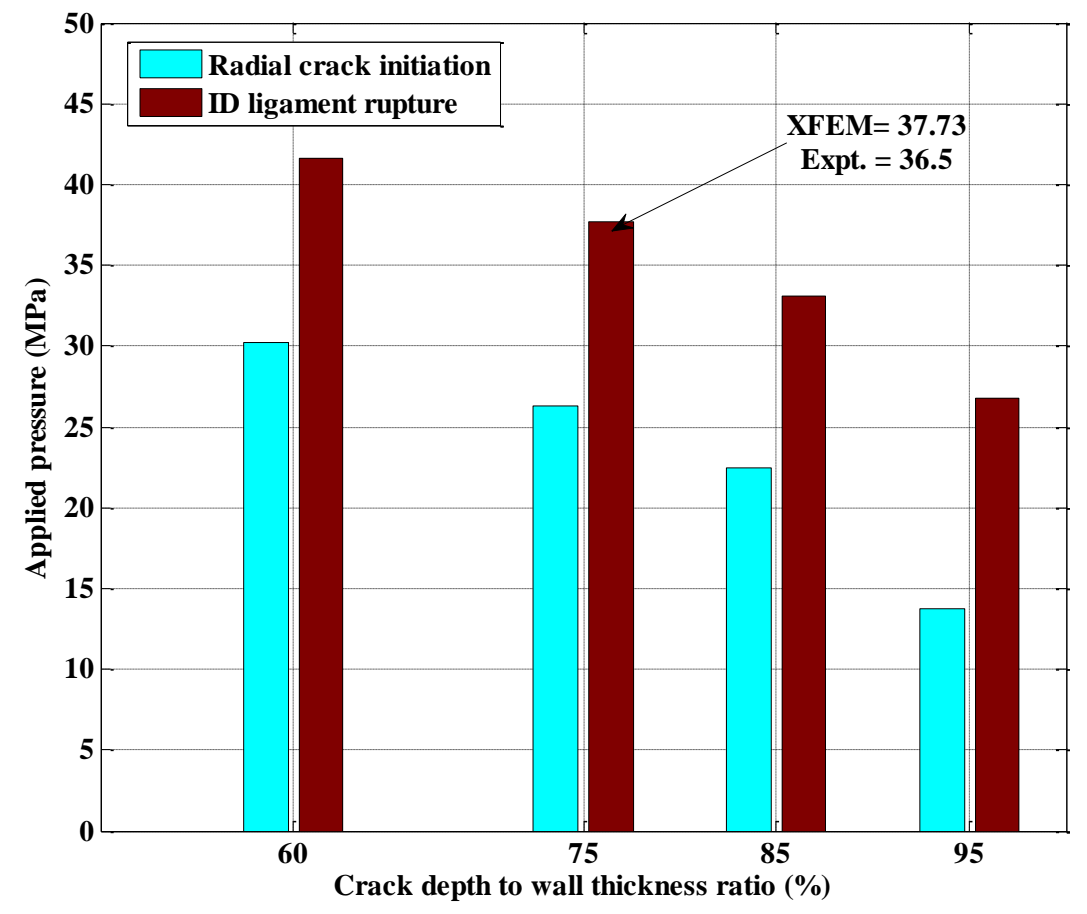

Figure 9 Radial crack initiation pressure and ID ligament rupture pressure with respect to different ratios of initial crack depth to wall thickness 


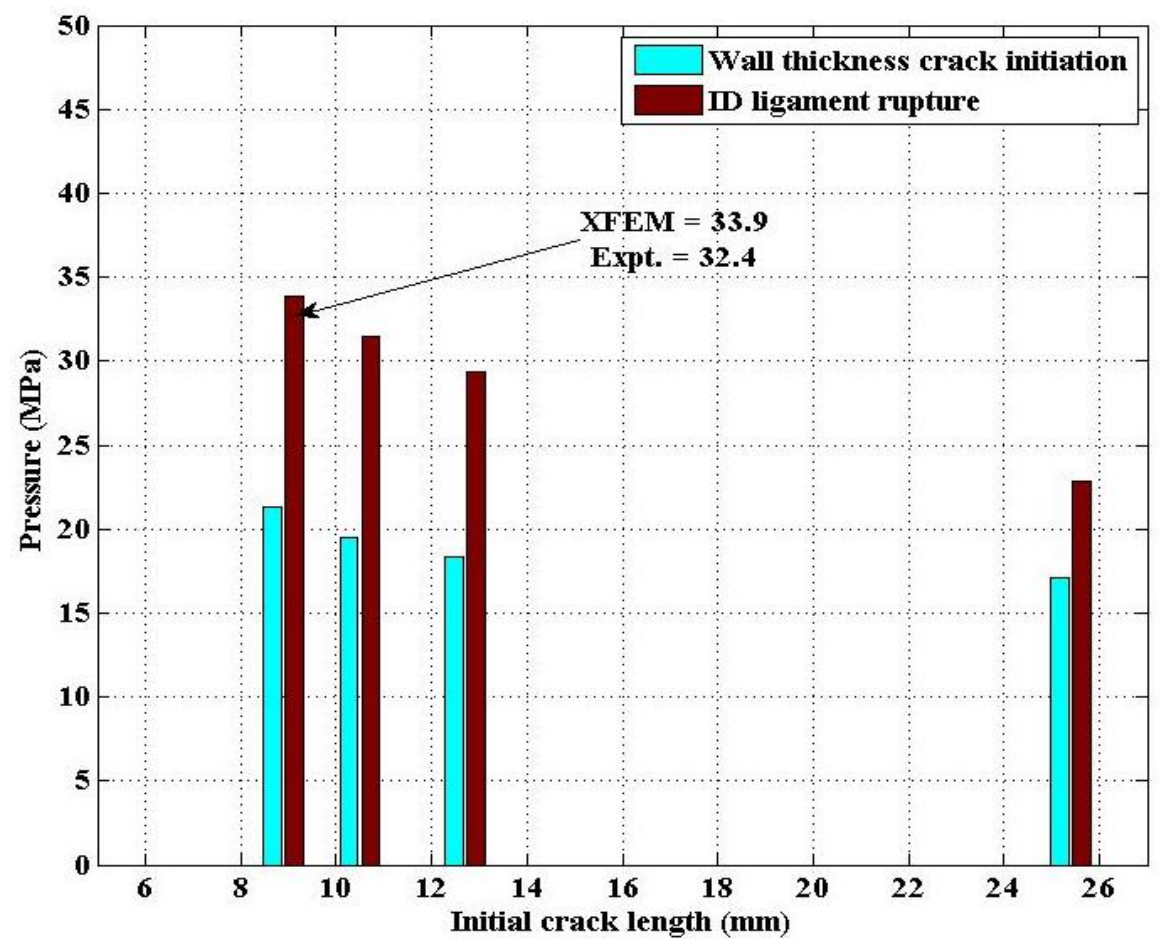

Figure 10 Radial or wall thickness crack initiation pressure and ID ligament rupture pressure with respect to different initial crack length

Table 2 Mesh size and estimated ligament rupture pressure for the 22.2-mm (7/8-in.) OD tube with an initial crack length of $6.35 \mathrm{~mm}$ and crack depth to wall thickness ratio of $75 \%$

\begin{tabular}{|l|l|l|l|l|l|}
\hline & Case-A & Case-B & Case-C & Case-D & Case-E \\
\hline $\begin{array}{l}\text { Along thickness } \\
\text { element length (mm) }\end{array}$ & 0.02 & 0.02 & 0.02 & 0.02 & 0.0635 \\
\hline $\begin{array}{l}\text { Along axial direction } \\
\text { element length (mm) }\end{array}$ & 1 & 0.1 & 0.5 & 1 & 0.5 \\
\hline $\begin{array}{l}\text { Along circumferential } \\
\text { direction element } \\
\text { length (mm) }\end{array}$ & 1 & 1 & 1 & 0.5 & 0.5 \\
\hline $\begin{array}{l}\text { Total number of } \\
\text { elements }\end{array}$ & 47,616 & $3,93,216$ & 86,016 & 63,488 & 35,840 \\
\hline $\begin{array}{l}\text { Estimated ligament } \\
\text { rupture pressure (MPa) }\end{array}$ & 37.7 & $\begin{array}{l}\text { Not } \\
\text { simulated }\end{array}$ & 36.9 & 37.5 & 36.3 \\
\hline
\end{tabular}




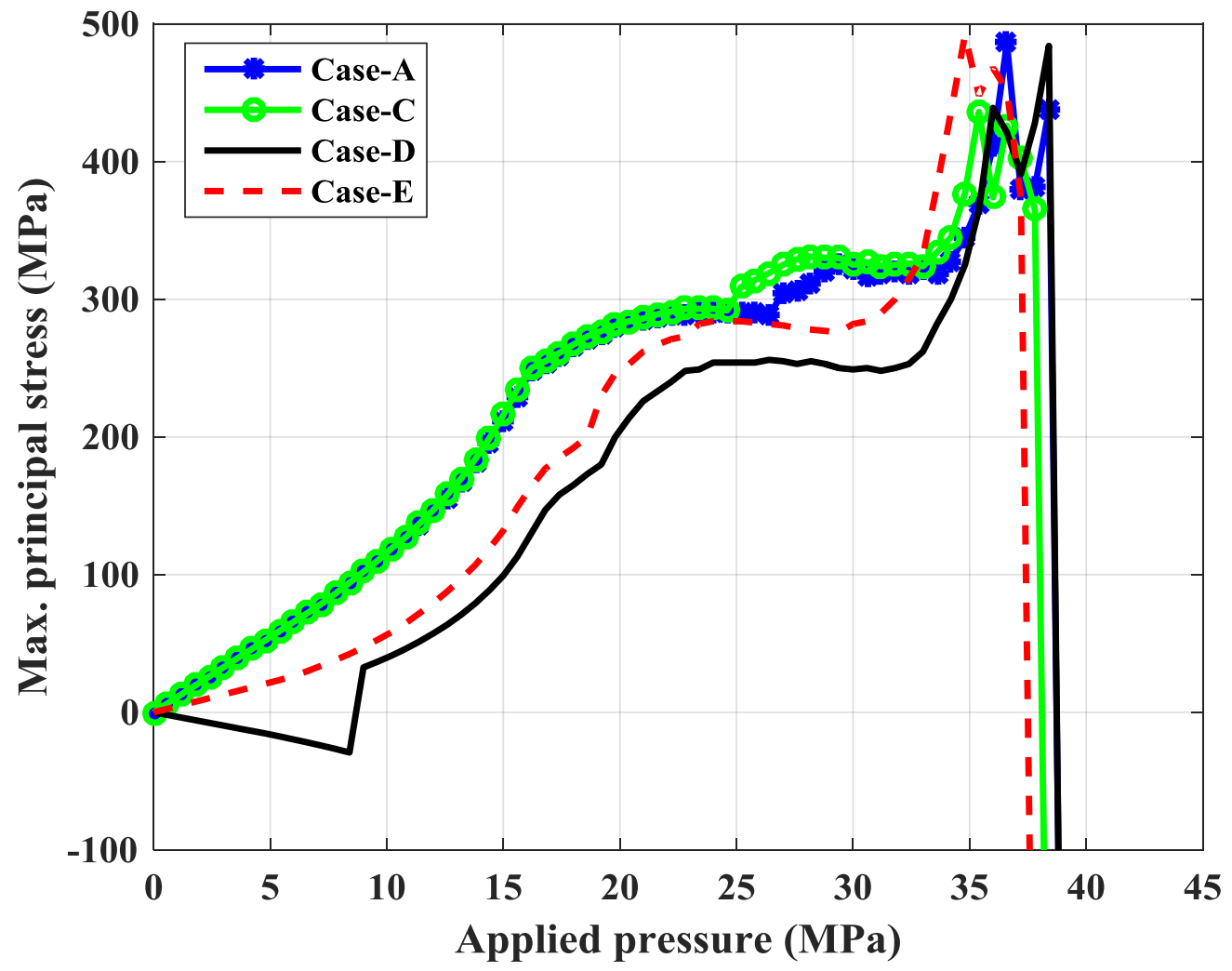

Figure 11 Simulated maximum principal stress history at the central (at center of crack) ID element for various test cases shown in Table 2

\subsection{SG tube model with two initial cracks for crack coalescence simulation}

In the second series of FE simulations, Alloy 600 SG tubes were modeled with two initial cracks to simulate crack coalescence. For this purpose, a 22.2-mm (7/8-in.) OD tube with different initial crack configurations was modeled. For example, Figure 12 shows the FEM model of the tube with two $72 \%$ part-through OD axial cracks, each with a length equal to 6.2 $\mathrm{mm}$. The two cracks are separated by an uncracked axial ligament of length $0.25 \mathrm{~mm}$. Figure 12 also shows an uncracked ligament of length $0.36 \mathrm{~mm}$ in the radial direction. The size of the elements along the axial and the radial direction of the uncracked ligaments were kept approximately of $0.02 \mathrm{~mm}$. Due to continuous pressurization, a sequence of events would occur that can be modeled through a single XFEM simulation. This model involves several consecutive events: First, the axial crack initiates at the crack-tip elements in the axial ligament. Second, the uncracked axial ligament is completely ruptured, creating a single partial through-wall crack. Third, the radial ligament crack initiates, propagates, and completely ruptures, creating a single $100 \%$ through-wall crack. Fourth, the tube ruptures unstably.

The predicted applied internal pressure corresponding to some of the above-mentioned events can be found in Table 3. For example, case 1 in Table 3 (refer also Figure 12) has an initial crack length of $12.7 \mathrm{~mm}(2 \mathrm{c}+\mathrm{b}), \mathrm{b}=0.25 \mathrm{~mm}$, and $\mathrm{a} / \mathrm{h}$ ratio of $72 \%$. After pressurization the model predicts that the axial ligament crack initiates at applied internal pressure of 15.86 
$\mathrm{MPa}$, the corresponding uncracked axial ligament of length $\mathrm{b}=0.25 \mathrm{~mm}$ completely ruptures at 16.81 $\mathrm{MPa}$, and the uncracked radial ligament completely ruptures at $30.97 \mathrm{MPa}$. The latter is well correlated with the experimentally measured radial ligament rupture pressure of $33.8 \mathrm{MPa}$. The FEM program stopped at $31.22 \mathrm{MPa}$, due to the convergence problem associated with large accumulated plastic strain and rapid unstable crack growth. The shapes of the OD surface at ID ligament rupture and final burst can be seen from Figures 13a and 13b, respectively. The corresponding variation in COD at OD and ID with respect to the applied pressure can be seen from Figure 14. As evident from the figures, after the ID ligament rupture, the COD grows unstably. Similar trends can also be observed from Figure 15, showing equivalent plastic strain at two OD and ID elements with respect to applied pressure. Figure 16 shows the equivalent plastic strain distribution near the ID crack region after the ID ligament ruptures at $30.97 \mathrm{MPa}$ applied pressure. This figure indicates substantial plastic strains, on the order of 20-25\%, at the time of ID ligament rupture.

Two additional cases with different initial cracks were also simulated, and the results are summarized in Table 3. In case 2, the two initial cracks were modeled with $2 c+b=12.7 \mathrm{~mm}$, $\mathrm{a} / \mathrm{h}=70$, and $\mathrm{b}=0.13 \mathrm{~mm}$. The FEM calculations estimated an ID ligament rupture pressure of 31.51 $\mathrm{MPa}$, which is well correlated with the experimental value of $33.8 \mathrm{MPa}$. In case 3 , two through-wall initial cracks were modeled with $2 c+b=12.7 \mathrm{~mm}, \mathrm{a} / \mathrm{h}=100$, and $\mathrm{b}=0.25 \mathrm{~mm}$. In this case, the crack initiation in the axial ligament is predicted to start at $3.8 \mathrm{MPa}$, which is well below the corresponding applied pressure of $15.86 \mathrm{MPa}$ for case 1 . Note that case 1 has the same initial crack and uncracked ligament lengths as case 3, but they differ in that $\mathrm{a} / \mathrm{h}$ is $72 \%$ for case 1 and $100 \%$ for case 3 . It is also predicted that the axial ligament rupture pressure for case 3 is 4.1 $\mathrm{MPa}$, which is also well below the axial ligament rupture pressure of $16.81 \mathrm{MPa}$ for case 1 .

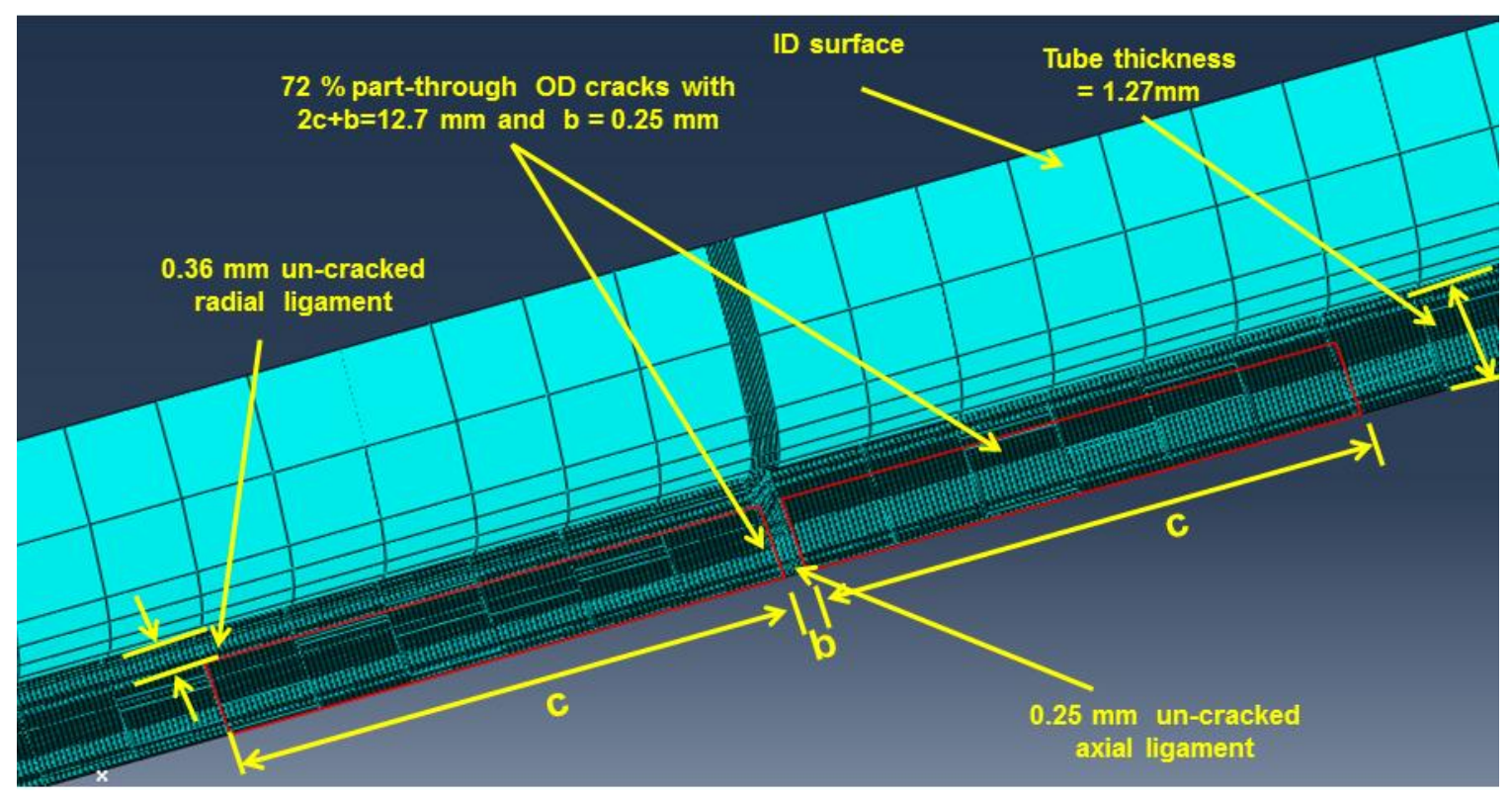

Figure 12 FEM model of 22.2-mm (7/8-in.) OD tube with two interacting initial cracks 

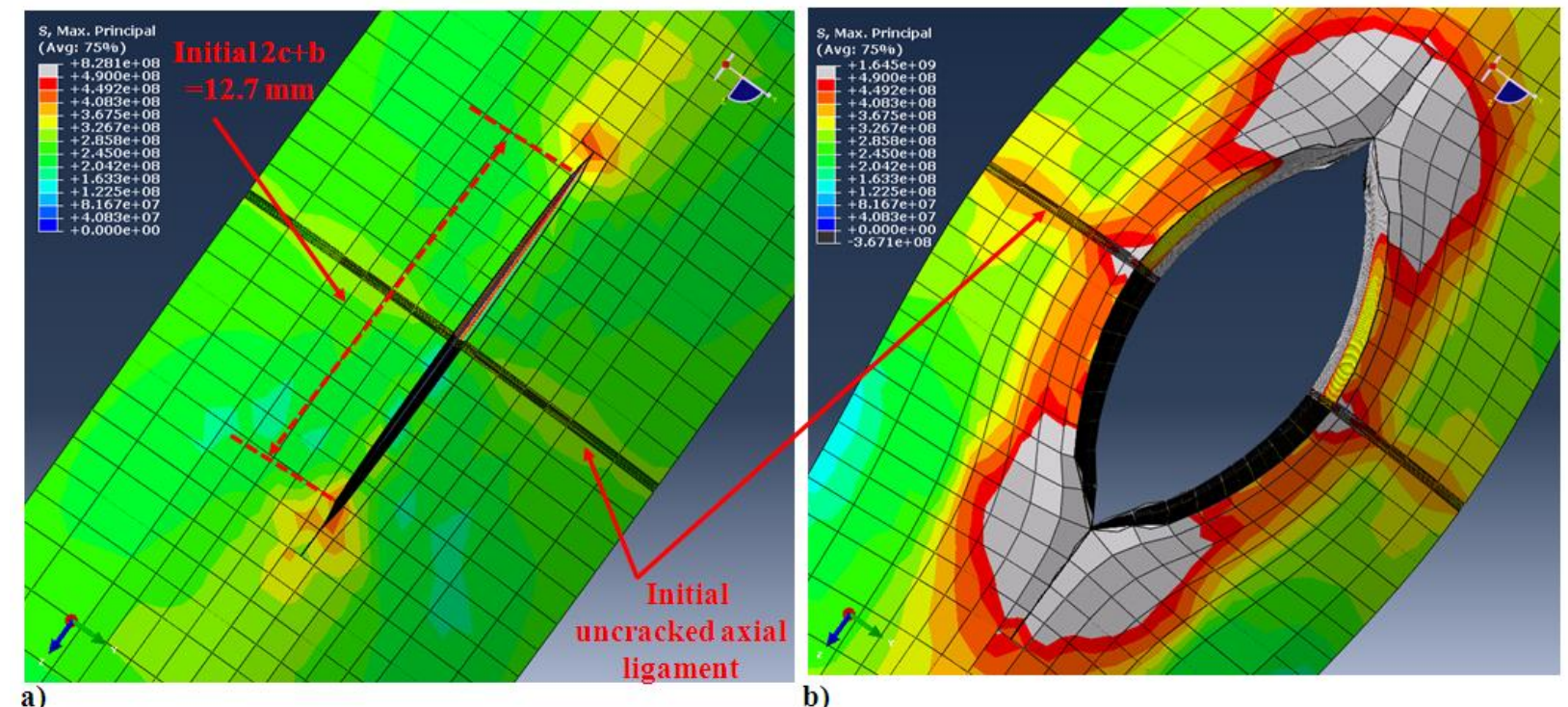

b)

Figure 13 Shape of the OD surface and maximum principal stress distribution for case 1 at (a) ID ligament rupture pressure (30.97 $\mathrm{MPa}$ ) and (b) final burst pressure (31.22 $\mathrm{MPa}$ )

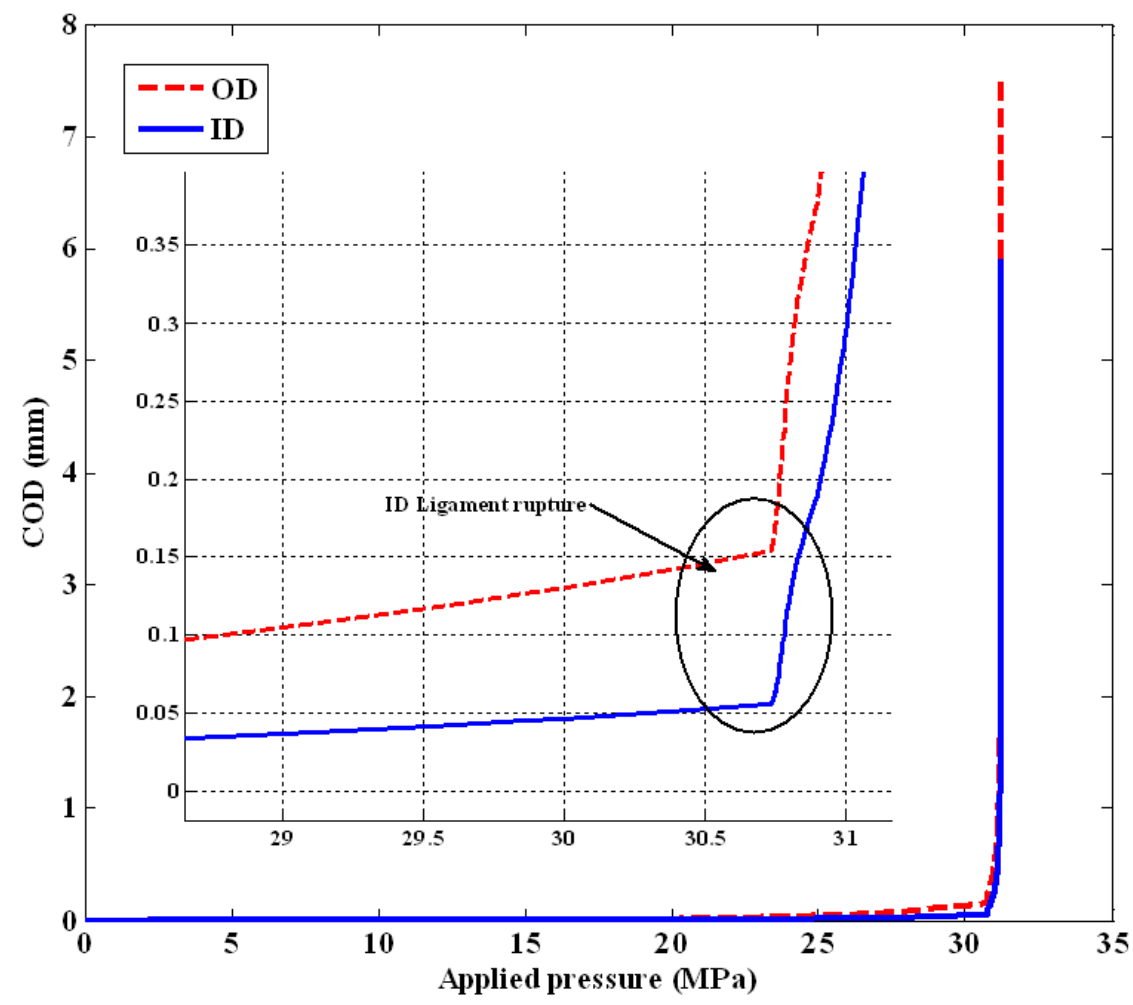

Figure 14 Estimated COD with respect to applied pressure at the OD and ID surface for case-1 tube (see Table 3.2) with $2 \mathrm{c}+\mathrm{b}=12.7 \mathrm{~mm}, \mathrm{a} / \mathrm{h}=72$, and $\mathrm{b}=0.25 \mathrm{~mm}$ 


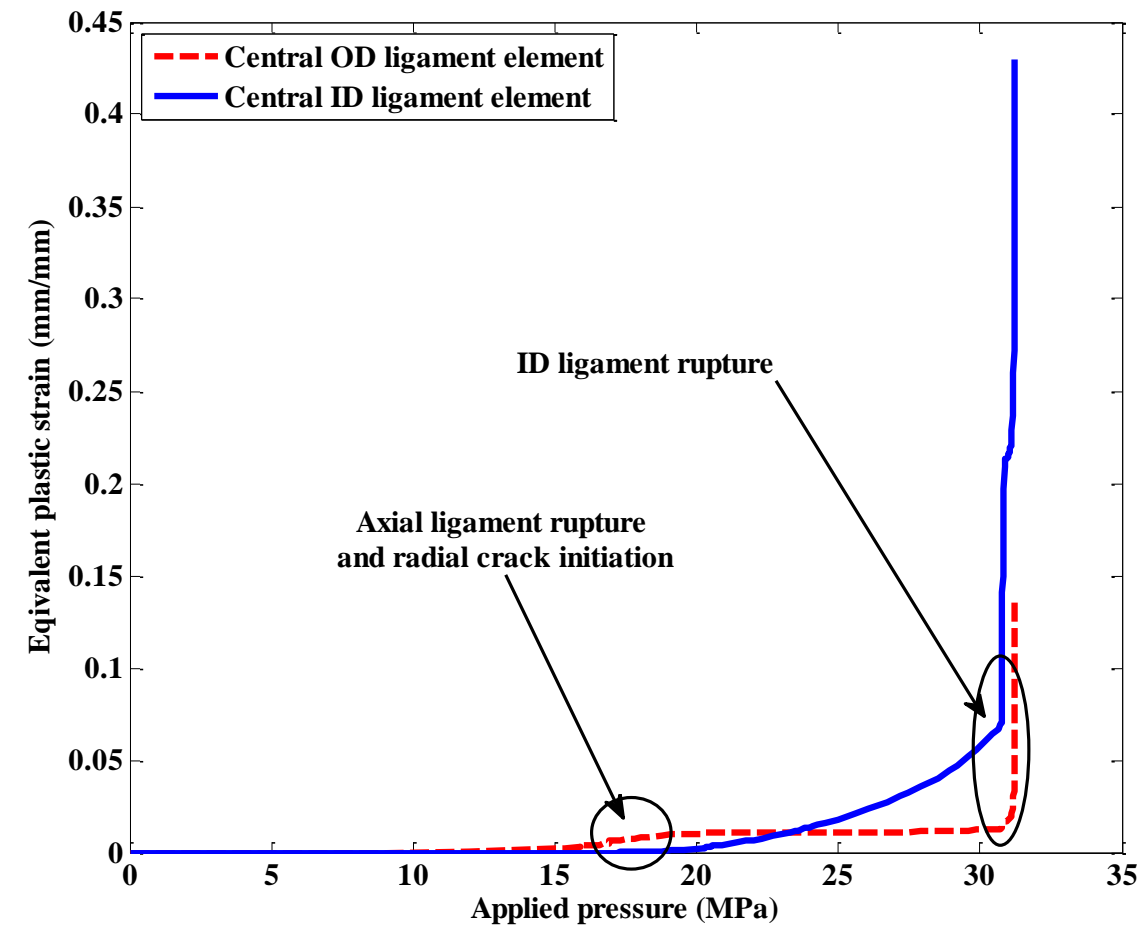

Figure 15 Estimated equivalent plastic strain with respect to applied pressure at the OD and ID surface for case- 1 tube (see Table 3.2) with $2 \mathrm{c}+\mathrm{b}=12.7 \mathrm{~mm}, \mathrm{a} / \mathrm{h}=72$, and $\mathrm{b}=0.25 \mathrm{~mm}$

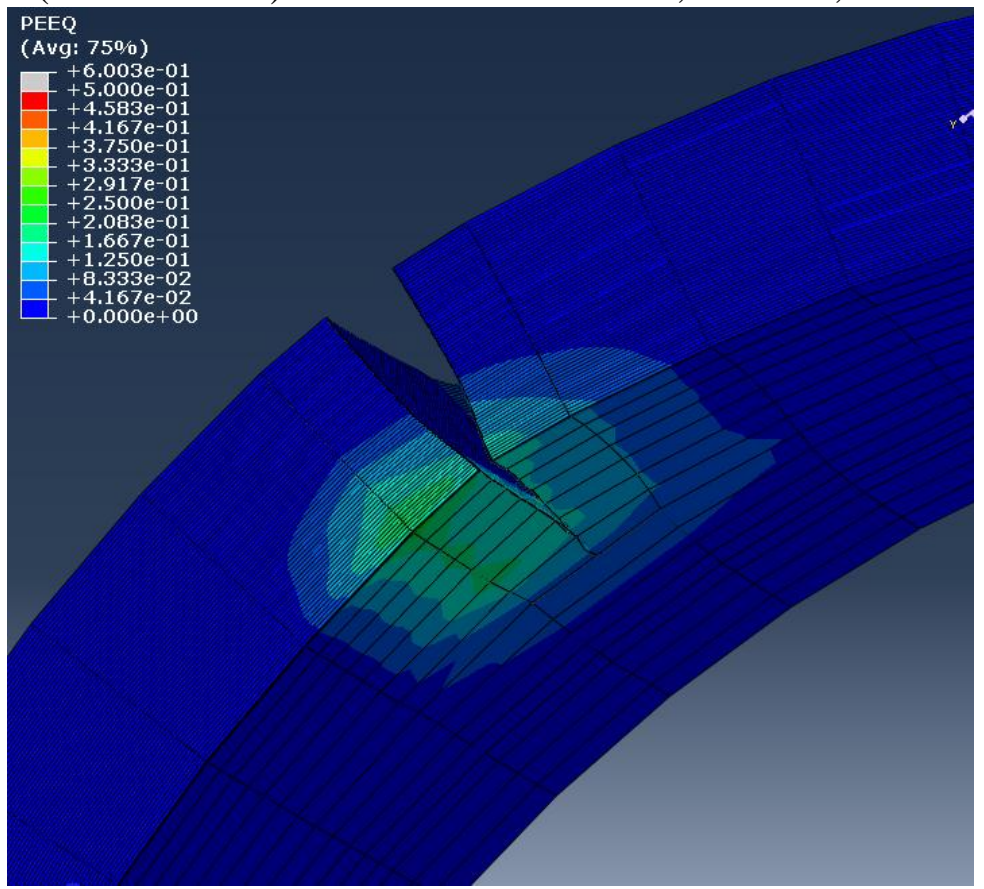

Figure 16 Distribution of equivalent plastic strain at $30.97 \mathrm{MPa}$ (radial ligament rupture pressure) for case-1 tube (see Table 3.2) with $2 \mathrm{c}+\mathrm{b}=12.7 \mathrm{~mm}, \mathrm{a} / \mathrm{h}=72$, and $\mathrm{b}=0.25 \mathrm{~mm}$ 
Table 3 XFEM and experimental results for three cases of crack coalescence model

\begin{tabular}{|c|c|c|c|c|c|c|}
\hline \multirow[b]{2}{*}{$\begin{array}{l}\text { Case } \\
\text { No. }\end{array}$} & \multirow[b]{2}{*}{$\begin{array}{l}\text { Initial crack } \\
\text { description }\end{array}$} & \multicolumn{4}{|c|}{ Pressure from XFEM model results (MPa) } & \multirow{2}{*}{$\begin{array}{c}\begin{array}{c}\text { Experimental } \\
\text { pressure } \\
(\mathrm{MPa})\end{array} \\
\text { Radial } \\
\text { ligament } \\
\text { rupture }\end{array}$} \\
\hline & & $\begin{array}{c}\text { Axial } \\
\text { ligament } \\
\text { crack } \\
\text { initiation }\end{array}$ & $\begin{array}{c}\text { Axial } \\
\text { ligament } \\
\text { rupture }\end{array}$ & $\begin{array}{c}\text { Radial } \\
\text { ligament } \\
\text { rupture }\end{array}$ & Burst & \\
\hline 1 & $\begin{aligned} \mathrm{a} / \mathrm{h} & =72 \% \\
2 \mathrm{c}+\mathrm{b} & =12.7 \mathrm{~mm} \\
\mathrm{~b} & =0.25 \mathrm{~mm}\end{aligned}$ & 15.86 & 16.81 & 30.97 & 31.2 & 33.8 \\
\hline 2 & $\begin{aligned} \mathrm{a} / \mathrm{h} & =70 \% \\
2 \mathrm{c}+\mathrm{b} & =12.7 \mathrm{~mm} \\
\mathrm{~b} & =0.13 \mathrm{~mm}\end{aligned}$ & 14.98 & 15.14 & 31.51 & 31.7 & 33.8 \\
\hline 3 & $\begin{aligned} \mathrm{a} / \mathrm{h} & =100 \% \\
2 \mathrm{c}+\mathrm{b} & =12.7 \mathrm{~mm} \\
\mathrm{~b} & =0.25\end{aligned}$ & 3.8 & 4.1 & NA & 22.3 & NA \\
\hline
\end{tabular}

\section{Conclusion}

Multiple XFEM models using commercially available ABAQUS software, were developed to predict crack initiation and propagation in Alloy 600 SG tubes with persisting crack(s). The results are compared with the experimental results that are available from the NRC-supported tube integrity program and were conducted at ANL. The XFEM predicted rupture and burst pressure results agree well with available experiment results at room temperature. This exercise shows that the ABAQUS based XFEM technique can effectively be used for rupture pressure estimation of SG tubes under design-basis accident conditions. We plan to use a similar technique to model stress corrosion cracking and/or fatigue crack growth, which are some of our future interests.

Acknowledgements: This research was sponsored by the U.S. Department of Energy, Office of Nuclear Energy, for the Light Water Reactor Sustainability Research and Development effort, under the program manager Dr. Jeremy Busby. Test results from the US-NRC-sponsored SGTIP program were used to validate the analytical results. 


\section{References}

1. U.S. Department of Energy (DOE), 2010, Nuclear Energy Research and Development Roadmap: Report to Congress, http://energy.gov/ne/downloads/nuclear-energy-research-and-developmentroadmap.

2. Busby, J.T., 2012, Light Water Reactor Sustainability Program Materials Aging and Degradation Pathway Technical Program Plan, ORNL/LTR-2012/327, Oakridge National Laboratory, Oakridge, TN.

3. Shah, V.N., and Macdonald, P.E., 1993, Ageing and Life Extension of Major Light Water Reactor Components, Elsevier Press.

4. Bakhtiari, S., Kasza, K. E., Kupperman, D. S., Majumdar, S., Park, J. Y., Shack, W. J., and Diercks, D. R., 2003, Second U.S. Nuclear Regulatory Commission International Steam Generator Tube Integrity Research Program - Final Project Summary Report, NUREG/CR-6804 (ANL-02/28).

5. Majumdar, S., 1999, "Prediction of structural integrity of steam generator tubes under severe accident conditions," Nuclear Engineering and Design, Vol-1941999, pp. 31-55.

6. Majumdar, 2001, "Structural analysis of electro sleeved tubes under severe accident transients," Nuclear Engineering and Design, Vol. 208, pp. 167-179.

7. Lee, J.H., Park, Y.W., Song, M.H., Kim, Y.J., and Moon, S.I., 2001, "Determination of equivalent single crack based on coalescence criterion of collinear axial cracks," Nuclear Engineering and Design, Vol. 205, pp. 1-11.

8. Abou-Hanna, J., McGreevy, T. E., and Majumdar, S., 2004, "Prediction of crack coalescence of steam generator tubes in nuclear power plants," Nuclear Engineering and Design, Vol. 229, pp. $175-187$.

9. Moon, S.I., Chang, Y.S., Kim, Y.J., Lee, J.H., Park, Y.W., and Song, M.H., 2007, "Determination of failure pressure for tubes with two non-aligned axial through-wall cracks," International Journal of Fracture, Vol. 144, pp. 91-101.

10. Chang, Y.S., Huh, N.S.,.J. Kim, Y.J., Lee, J.H., and Choi, Y.H., 2007, "Coalescence evaluation of collinear axial through-wall cracks in steam generator tubes," Nuclear Engineering and Design, Vol. 237, pp. 1460-1467.

11. Babuska, I., Caloz, G., and Osborn, J., 1994, "Special finite element methods for a class of second order elliptic problems with rough coefficients," SIAM Journal on Numerical Analysis, Vol. 31, pp. 945-981.

12. Melenk, J., and Babuska, I., 1996, "The partition of unity finite element method: Basic theory and applications," Computer Methods in Applied Mechanics and Engineering, Vol. 39, pp. 289-314.

13. Sethian, James A., 1999, Level Set Methods and Fast Marching Methods: Evolving Interfaces in Computational Geometry, Fluid Mechanics, Computer Vision, and Materials Science, Cambridge: Cambridge University Press.

14. Belytschko, T., and T. Black, 1999, "Elastic crack growth in finite elements with minimal remeshing," International Journal for Numerical Methods in Engineering, Vol. 45, pp. 601-620.

15. Sukumar, N., Moes, N., Moran, B., and Belytschko, T., 2000, "Extended finite element method for three-dimensional crack modeling," International Journal for Numerical Methods in Engineering, Vol. 48 (11), pp. 1549-1570.

16. Sukumar, N., Chopp, D. L., Bechet, E., and Moes, N., 2008, "Three-dimensional nonplanar crack growth by a coupled extended finite element and fast marching method," International Journal for Numerical Methods in Engineering, Vol. 76(5), pp.727-748 .

17. Shi, J., Chopp, D., Lua, J., Sukumar, N., Belytschko. T., 2010, “ABAQUS implementation of extended finite element method using a level set representation for three-dimensional fatigue crack growth and life predictions," Engineering Fracture Mechanics, Vol. 77, pp. 2840-2863.

18. Bordas, S. P. A., Natarajan, S., Kerfriden, P.,, Augarde, C. E., Mahapatra, D. R., 
Rabczuk, T., Dal Pont, S., 2011, "On the performance of strain smoothing for quadratic and enriched finite element approximations (XFEM/GFEM/PUFEM)," International Journal for Numerical Methods in Engineering, Vol. 86, pp. 637-666.

19. Rabczuk, T., and T. Belytschko. "Cracking particles: a simplified meshfree method for arbitrary evolving cracks." International Journal for Numerical Methods in Engineering 61, no. 13 (2004): 2316-2343.

20. Rabczuk, T., and T. Belytschko. "A three-dimensional large deformation meshfree method for arbitrary evolving cracks." Computer Methods in Applied Mechanics and Engineering 196, no. 29 (2007): 2777-2799.

21. Rabczuk, Timon, Stéphane Bordas, and Goangseup Zi. "A three-dimensional meshfree method for continuous multiple-crack initiation, propagation and junction in statics and dynamics." Computational Mechanics 40, no. 3 (2007): 473-495.

22. Amiri, Fatemeh, C. Anitescu, M. Arroyo, S. P. A. Bordas, and Timon Rabczuk. "XLME interpolants, a seamless bridge between XFEM and enriched meshless methods." Computational Mechanics 53, no. 1 (2014): 45-57.

23. Zhuang, Xiaoying, C. E. Augarde, and K. M. Mathisen. "Fracture modeling using meshless methods and level sets in 3D: framework and modeling." International Journal for Numerical Methods in Engineering 92, no. 11 (2012): 969-998.

24. Areias, Pedro, T. Rabczuk, and P. P. Camanho. "Finite strain fracture of 2D problems with injected anisotropic softening elements." Theoretical and Applied Fracture Mechanics 72 (2014): 50-63.

25. Areias, P., T. Rabczuk, and D. Dias-da-Costa. "Element-wise fracture algorithm based on rotation of edges." Engineering Fracture Mechanics 110 (2013): 113-137.

26. Areias, Pedro, and T. Rabczuk. "Finite strain fracture of plates and shells with configurational forces and edge rotations." International Journal for Numerical Methods in Engineering 94, no. 12 (2013): 1099-1122.

27. Song, Jeong-Hoon, Pedro Areias, and Ted Belytschko. "A method for dynamic crack and shear band propagation with phantom nodes." International Journal for Numerical Methods in Engineering 67, no. 6 (2006): 868-893.

28. Chau-Dinh, Thanh, Goangseup Zi, Phill-Seung Lee, Timon Rabczuk, and Jeong-Hoon Song. "Phantom-node method for shell models with arbitrary cracks." Computers \& Structures 92 (2012): 242-256.

29. Rabczuk, Timon, Goangseup Zi, Axel Gerstenberger, and Wolfgang A. Wall. "A new crack tip element for the phantom-node method with arbitrary cohesive cracks." (2008), http://ir.canterbury.ac.nz/handle/10092/1796.

30. Rabczuk, Timon, Robert Gracie, Jeong-Hoon Song, and Ted Belytschko. "Immersed particle method for fluid-structure interaction." International Journal for Numerical Methods in Engineering 22, no. 1 (2010): 48.

31. ABAQUS 6.13 Documentation, 2013, Dassault Systèmes Simulia Corp.

32. Benzeggagh, M. L., and M. Kenane. "Measurement of mixed-mode delamination fracture toughness of unidirectional glass/epoxy composites with mixed-mode bending apparatus." Composites science and technology 56, no. 4 (1996): 439-449.

33. Camanho, Pedro P., and Carlos G. Dávila. "Mixed-mode decohesion finite elements for the simulation of delamination in composite materials." (2002), NASA/TM-2002-211737, L-18194, NAS 1.15:211737.

34. Elices, M., Guinea, G. V., Gomez, J., Planas, J., 2002, "The cohesive zone model: 
Advantages, limitations and challenges," Engineering Fracture Mechanics, Vol. 69, pp. 137163.

35. Bonifaz, E. A., 2011, "Cohesive zone modeling to predict failure processes," Canadian Journal on Mechanical Science and Engineering, Vol. 2, pp.42-53. 